\title{
Could a short training intervention modify opinions about mental illness? A case study on French health professionals
}

\author{
Murielle Villani ${ }^{1,2^{*}}$ (D) and Viviane Kovess - Masfety ${ }^{1,2,3}$
}

\begin{abstract}
Background: In France, negative views on schizophrenia are pervasive, even among health professionals. Prior research suggests that the level of prejudice is lower when the illness is described with the example of a specific individual. This finding highlights the importance of designing local, targeted destigmatization campaigns. The present study aims to evaluate the benefits of a short intervention offering contact with psychiatric services users on reducing the stigma about mentally ill people, among a sample of Health Administrators and Students.
\end{abstract}

Methods: Data were collected before (Time 0) and after (Time 1) a short training intervention program proposed to a sample of 121 Health Services Administrators and Students. This four-day workshop explained the multiple causes of mental illness, the clinical implications of psychosis and various mental disorders, the subjective experience of mental illness and the legal evolutions of users' rights. The intervention was strongly based on live testimonies from users. Using a French version of the Attitudes to Mental IIIness scale, we compared attitudes before and after the training intervention among 58 trainees having answered our questionnaire at Time 0 and Time 1.

Results: After the training, a significantly lower endorsement of stigmatizing statements compared to baseline was found in one third (9 out of 27) of the items. These results plead for further research about the potential benefits of initiatives like this short intervention program on significantly reducing stigmatizing attitudes towards mentally ill people among Health Administrators and Students.

Conclusions: The present study highlights the importance of further studying the effect of targeted interventions that offer first hand contact with persons with mental illness.

Keywords: Mental illness, Stigma, Attitudes, Targeted intervention, Health services professionals

\section{Background}

Prejudice and discrimination towards people suffering from mental illness are common and socially damaging $[1,2]$. This stigma contributes to negative outcomes, self-stigmatization and low self-esteem among persons with mental illness [3, 4]. However, attitudes towards mental illness can be modified over time by shifts in social perceptions or through media campaigns focused on mental health literacy about a disorder [5-8]. In France as in a number of other countries, negative views on schizophrenia are pervasive. Indeed, while the French

\footnotetext{
* Correspondence: muriellevillani@gmail.com

${ }^{1}$ Fondation Pierre Deniker, 36 avenue Raymond Poincaré, Paris, France ${ }^{2}$ Laboratoire de Psychopathologie et Processus de Santé, Paris Descartes University, Paris EA4057, France

Full list of author information is available at the end of the article
}

are generally more familiar with the names of psychiatric disorders, as compared to Australians or Scots, there remains a clear lack of knowledge about mental illness as well as negative stereotypes about severe mental disorders including psychosis, and in particular schizophrenia [9]. That being said, in a large study on knowledge and attitudes toward severe mental disorders, when descriptors related to a person with a mental illness, prejudice was less overt [9]. This finding led to the conclusion that using personal testimonies and raising the visibility of persons with mental disorders in the community is likely to be more effective than generic campaigns in reducing stigma [9].

There have been several studies evaluating the effects of destigmatization campaigns. A recent literature review 
established that generic one-time campaigns have yielded limited results [10]. Studies quoted in the latter literature review have established that, in order to be efficient, interventions should focus on specific targets, include a follow-up over time, and include contact with psychiatric services users and their families [10]. In addition, the goals of such an intervention should be determined as a function of real users' experience, and be accompanied by tangible evolutions in professional practice and social insertion of mentally ill people [10].

Literature reviews confirm the effectiveness of contactbased strategies for stigma reduction, in the general population as well as among health professionals [11-13]. For instance, contact-based education included in pharmacist students' curricula in the form of social interactions with a person suffering from a mental illness, has proven to be effective in reducing mental health related stigma [14].

The present paper reports on a short training intervention aimed at exploring the modifications of attitudes towards people suffering from severe mental illness. The intervention was provided in the curriculum of the French National School of Public Health where public health services administrators are mandatorily trained. It was hypothesized that such training integrated into their curriculum as initial or continuing education, based on adapted scientific and clinical information together with life testimonies of users, would increase acceptance towards persons with mental illness. In addition, it was hypothesized that these health services professionals may help improve access to care and participate in the evolution of attitudes in the general population, resulting in a better integration of users into society. Indeed, they could play a strategic role in the delivery of care and in developing non-institutionalized care.

This shift was evaluated using the Attitudes to Mental Illness scale, the instrument used in the National United-Kingdom opinion surveys. We compare the attitudes and opinions of our sample before and after the intervention.

\section{Methods}

\section{The short training intervention}

The intervention was a four-day workshop focused on fundamental notions in psychiatry hosted at the school. It was designed to improve attendees' knowledge about the multiple causes of mental illness, the clinical implications of psychosis and various mental disorders at all ages (schizophrenia, bipolar disorder, anxiety disorders, depression, eating disorders, addictions to alcohol and drugs, autism, behavior problems, perversions), the subjective experience of mental illness, and the legal evolution of users' rights.

The workshop was not only designed and delivered by psychiatrists working in the field, but was also based on testimonies of psychiatric services users about their lives. These consumers had been contacted through users and families associations (Unafam, Profamille, Société française d'Alcoologie), had chosen to testify voluntarily, and were present in person on the training session location. They suffered from various mental disorders, in particular schizophrenia, bipolar disorders, anorexia or alcoholism. Users present to share their experience were free to organize their talk as they pleased and were compensated for their time. Testimonies lasted $30 \mathrm{~min}$ each, followed by a session with an opportunity for attendees to ask questions. Users shared their experiences regarding the consequences of their illness, their feelings about their symptoms and about psychiatric services. The sharing of personal experience represented the specificity of the training, in the hope that this would help modify perceptions of mentally ill persons and help better understanding them as individuals, as opposed to abstract representations that are often linked with dangerousness and weirdness. In practice, the sessions were a real discovery for most of the students, and always a moving moment for attendees as well as for speakers.

In addition, a film club was organized with a debate following the projection of a large audience movie presenting a character suffering from severe mental illness.

\section{Sample}

The sample consisted of 121 Public Health Services administrators having attended an optional short training program about fundamental notions in psychiatry, in the context of their curriculum at the Ecole des Hautes Etudes en Santé Publique (EHESP), the National French school for Studies in Public Health. The school is a public institution, which provides training and conducts research in the field of public health.

Among the 121 eligible participants, 70 attended the training program in 2012 and 51 in 2014; 91 were women and 30 were men, and 90 were Students in Initial Training and 31 were Health Services Professionals (Managers or Administrators) in Continuing Education.

Overall, our sample consisted of 58 people having participated to the study before (Time 0 ) and after (Time 1) the training: 10 men and 48 women. Among them, 48 were students in Initial Training and 10 were Health Services Professionals (Managers or Administrators) in Continuing Education.

Time 0 assessments took place at the time of preregistration for the workshop ( 2 to 3 weeks before the workshop), and Time 1 took place on average 8 days after the workshop, within a maximum of 30 days.

All respondents had volunteered for the optional training program in the context of their curriculum, and provided verbal informed consent for participation in this study. The study was carried out in compliance with the 
Helsinki declaration, and the rules in application in France and at the school. The program itself was approved by the Education Council and the Administrative Council of EHESP. Anonymity of all individual results has been respected all along the procedure.

\section{Instrument}

The Attitudes to Mental Illness scale was designed to survey annually the attitudes towards mental illness among adults in England and Scotland at an initiative of the Department of Health. The questionnaire consists of 26 items derived from the Community Attitudes Toward the Mentally Ill (CAMI) scale [15]. The latter scale itself derives from the Opinions about Mental Illness [16] survey, with a greater focus on attitudes concerning the acceptance of mentally ill persons and/or mental health facilities in the community. The Community Attitudes Toward the Mentally Ill (CAMI) has shown good validity and demonstrated its usefulness as explanatory and predictive variables for studying attitudes in the community [15]. For the development of the Attitudes to Mental Illness questionnaire, the number of items was reduced to 26 and a 27th item about employment was added in 2000.

The questionnaire consists of a series of statements expressing a similar number of positive and negative views about mental illness and related to areas such as perceptions of mental illness, social distance from mentally ill people, the responsibility of society towards the mentally ill, the role of such people in society and the treatments for mental illness [17].

For analysis, the statements are generally categorized in four dimensions:

- Fear and exclusion of mental illness

- Integration of the mentally ill into the community

- Understanding and tolerance towards the mentally ill

- Causes of mental illness and needs for specialized services [18].

In the present study, the 27 items of the Attitudes to Mental Illness scale were translated into French by a bilingual translator, back translated, and adapted to French culture (Additional file 1). Respondents were asked to what extent they agreed or disagreed with each statement, with responses ranging from 1 ("strongly Disagree") to 4 ("strongly Agree"). Since we aimed to measure the reduction of stigma between Time 0 (before the training) and Time 1 (after the training), the scoring of 14 statements was reversed.

The Community Attitudes Toward the Mentally Ill (CAMI), from which the Attitudes to Mental Illness scale derives, has been partially validated on a Frenchspeaking sample, through one of its subscales, the Community Mental Health Ideology scale [19]. Also, some items of the Attitudes to Mental Illness scale correspond to similar items that have been validated previously for the purpose of a vignette-based population survey about attitudes and beliefs of the general French population about schizophrenia and major depression, conducted in 2013 [20]. Without being formally validated on a French sample, the Attitudes to Mental Illness scale has previously shown good psychometric qualities for some of its subscales/items on French and French-speaking samples. Also, the French version of the scale in the present sample showed good internal consistency with a Cronbach Alpha of .824.

\section{Data analysis}

Data was analyzed using IBM SPSS Statistics 20 (Statistical Package for the Social Sciences, SPSS Inc., Chicago, IL). Missing values, representing less than 1,9\% of the responses, were replaced using the Expectation Maximization procedure. A Shapiro-Wilk test showed that some items had highly skewed data distributions. In order to address this issue, a non-parametric test, the Wilcoxon signed-rank test for ordinal data in paired samples, has been used. The Wilcoxon test is frequently used to investigate pre-post scores in a sample of the same participants and is well adapted to skewed distributions. An alpha level of .05 was used to determine the significance of the results.

Mean scores to each item were used to perform data analysis, as it is the way the Attitudes to Mental Illness scale has been used in longitudinal researches in other European countries, which offers data for reference [17].

As mentioned in the previous section, the scoring of 14 statements has been reversed in order to align with a systematical stigmatizing trend. The items to which we have applied a reverse scoring are designated in Table 1 (Results).

\section{Results}

Reduction of stigma between T0 and T1

We identified a significant reduction of stigma between Time 0 (before the training) and Time 1 (after the training), among the 58 respondents. A reduction of stigma equals to a decrease in the mean scores, which corresponds to a decrease in the level of agreement with stigmatizing statements. More precisely, one third of the statements ( 9 out of 27) - that is to say 5 statements of the Dimension "Integration", 2 statements of the Dimension "Fear and exclusion", one statement of the Dimension "Understanding and tolerance", and one statement of the Dimension "Causes of mental illness and needs for special services" - showed a significant or very significant reduction of stigma.

As shown in Table 1, within the theme "Integration of the mentally ill into the community », 4 statements 


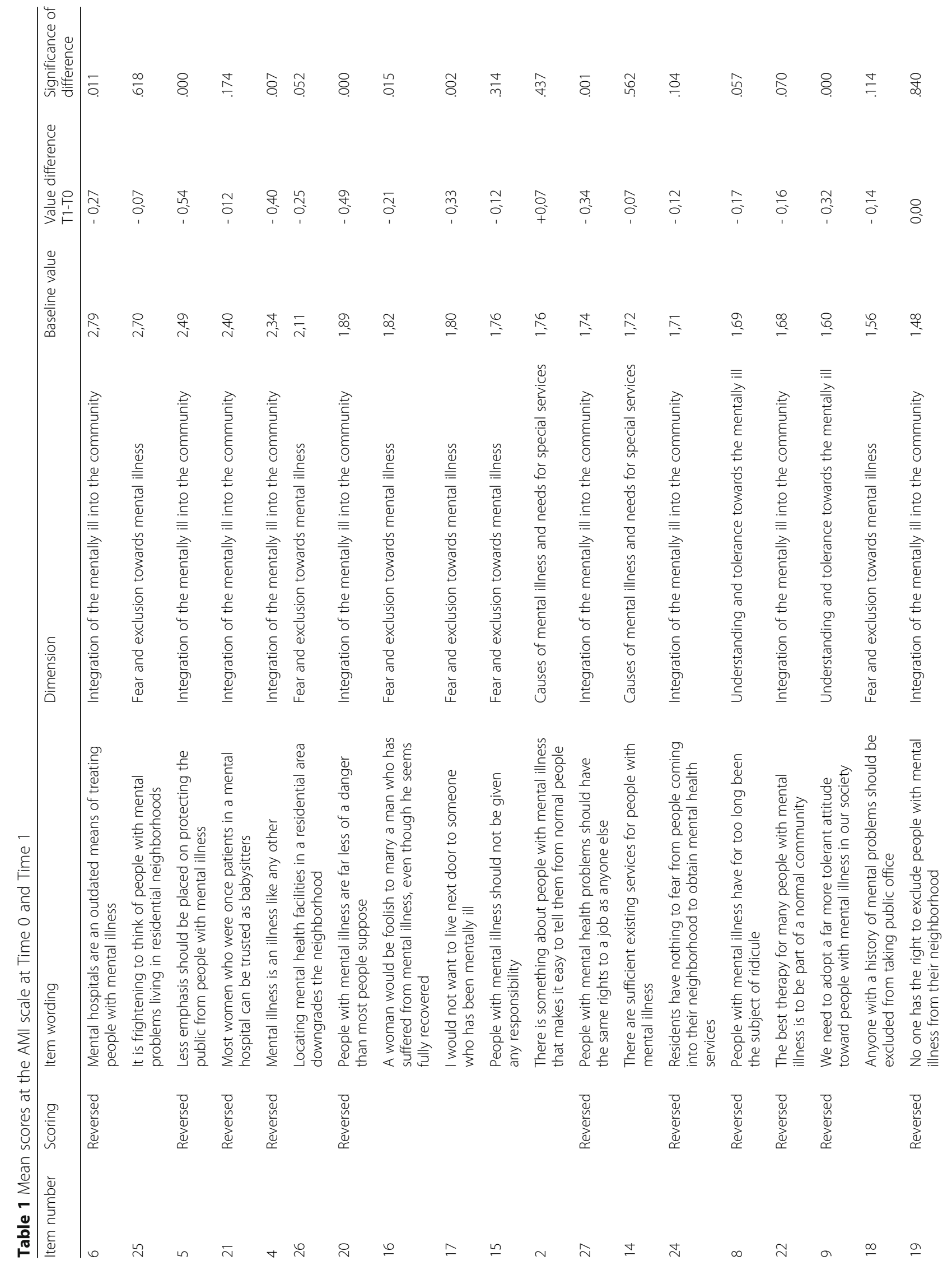




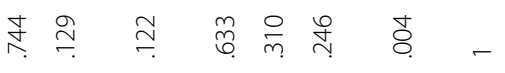

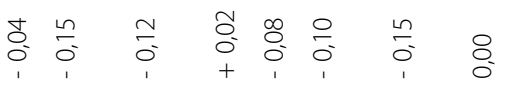

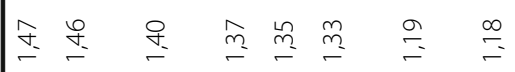

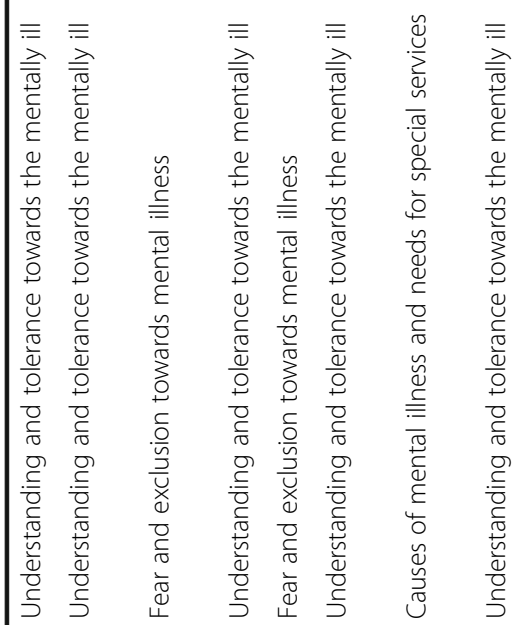

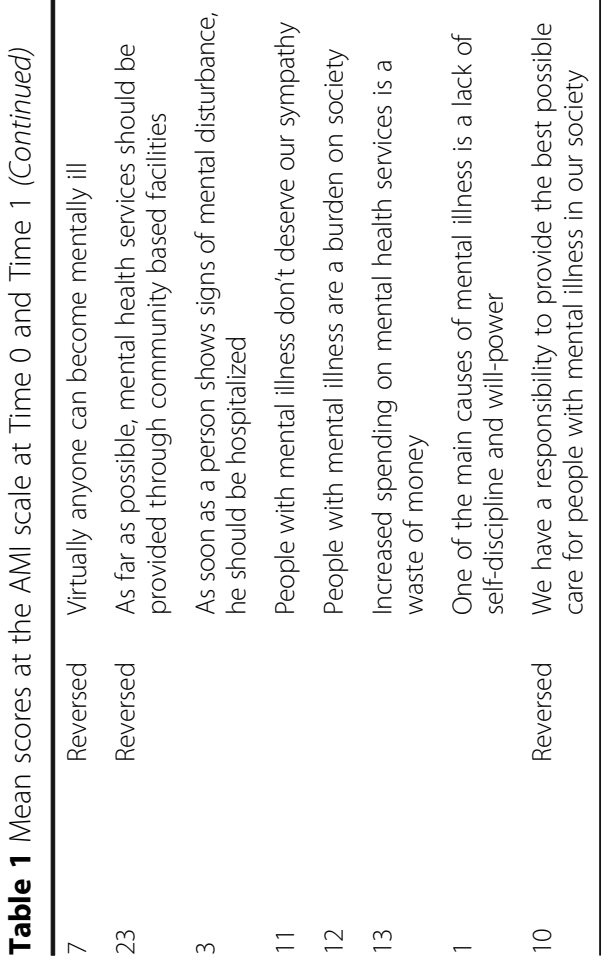


showed a very significant reduction of stigma $(p<.01)$ and one statement a significant reduction of stigma $(p<.05)$. The 4 statements with the most significant changes were the following:

- "Less emphasis should be placed on protecting the public from people with mental illness" (reversed)

- "Mental illness is an illness like any other"

- "People with mental illness are far less of a danger than most people suppose"

- "People with mental health problems should have the same rights to a job as anyone else".

The statement "Mental hospitals are an outdated means of treating people with mental illness" has seen its level of agreement decrease significantly $(p=.011)$. Although not significant, the decrease of agreement between Time 0 and Time 1 with the statement "The best therapy for many people with mental illness is to be part of a normal community" tends to significance $(p=.07)$, showing that, in total, the dimension of "Integration" has evolved for many items.

After the training, the respondents were also less likely to agree with negative statements related to the fear and exclusion of mentally ill persons. The statements where the reduction was significant or very significant within the theme "Fear and exclusion towards mental illness", were the following:

- "I would not want to live next door to someone who has been mentally ill" ( $p=.002)$,

- "A woman would be foolish to marry a man who has suffered from mental illness, even though he seems fully recovered $»(p=.015)$.

Also, the reduction of agreement with the statement "Locating mental health facilities in a residential area downgrades the neighborhood" is very close to significance $(p=.052)$.

Regarding the understanding of stigmatization, we noted in particular a very significant decrease in mean scores, meaning actually an increase (scoring has been reversed) of agreement with the statements saying "We need to adopt a far more tolerant attitude toward people with mental illness in our society" ( $p=.000)$.

Regarding the "Causes of mental illness and needs for special services ", there was a very significant decrease $(p=.004)$ in the notion of self-generated cause for mental illness. Thus, after the training, stigma mean score of the respondents decreased significantly on the statement "One of the main causes of mental illness is a lack of self-discipline and will-power".

No significant differences were found relating to the reduction of stigma as a function of attendees' gender and type of trainees (Initial Training versus Continuing Education).

\section{Discussion}

The present study showed a lower level of agreement with stigmatizing statements, or a higher level of agreement with tolerant statements, as compared with other studies using the same instrument $[17,21]$. In particular, most of the "Integration" and "Fear and exclusion" statements showed a significant reduction of stigma, suggesting an improvement in the perception of dangerousness and disturbance attached to persons with mental illness, a growing sense of integration in day-to-day life (neighborhood, marriage, employment), a shift towards the view that mental illness is similar to medical illness - a "mental illness is like any other illness" attitude -, and the expression of needs for ambulatory treatments and community-based therapies. Some statements of the latter two dimensions have also shown a reduction of stigma that almost reaches significance.

According to the literature, these findings can be linked with the higher education of our sample of students and professionals. Indeed, studies have generally shown that people with higher education and higher socio-economic status have more positive attitudes toward mentally ill people than the general population [22].

The status of health administrators or students of the respondents in our sample might also explain some differences in terms of the perceived level of services required for the mentally ill people. However, this is difficult to analyze in the present study, as Health Administrators in Continuing Education represent a limited proportion of the sample. That being said, similarly to other studies on contact-based education designed for health professionals $[11,13]$, our study highlights the importance of actual testimonies of consumers. Medical students and health professionals are described in the literature in this field as comparable to the general population, in their opinions about mental illness, even if the findings in this area have sometimes been controversial. Indeed, even if they have more knowledge and accept less restrictions toward mentally ill people, health professionals have as many negative stereotypes and the same social distance towards persons with mental illness, especially schizophrenia, as the general public [23]. A large review on the complex relationship between stigma and mental health professionals has shown that the latter can be stigmatizers, agents of destigmatization, as well as stigma recipients [24].

No significant differences between genders and types of trainees (Initial Training versus Continuing Education) were found, and this is in contrast with existing findings in, for example, the England Attitudes to 
Mental Illness Research Report findings, and other studies in which increased age, female gender and a high education level have also been associated with more tolerance and more positive attitudes $[25,26]$. This could be explained by the small sample size of the present study and the small percentage of men and persons in Continuing Education.

The reduction of stigma measured after the short training intervention related to statements that were for the most regrouped in the themes "Integration" and "Fear and exclusion". Interestingly, greater integration and less exclusion were also significant positive evolutions identified by the longitudinal analysis of the England Attitudes to Mental Illness survey between 1994 and 2012. This could mean that the statements about integration, fear and exclusion (or its counterpart, acceptance) are the most susceptible to change. Further research would be needed to explore these results.

In the present study, one must note that some items revealed at baseline a relatively low level of acceptance with negative and stigmatizing statements. More specifically, most of the 10 statements with the lower level of acceptance of stigmatization, visible at the end of Table 1 (which is organized following a decreasing order of baseline value), have not known significant changes between Time 0 and Time 1. This might be explained by the fact that there was little possibility to reduce stigma more on these particular subjects. For instance, the very low level of agreement with the exclusion of people with mental illness from public office may be associated with the fact that the French law has been imposing quotas of employment of handicapped people, among which mentally handicapped people, for decades, after the Law of July $10^{\text {th }} 1987$.

An important difference between our results and those from the longitudinal analysis in England is that the statement "One of the main causes of mental illness is a lack of self-discipline and will-power" presents a very significant $(p=.004)$ decrease of agreement after training, whereas in the England longitudinal analysis, no significant change was noticed over time. This may suggest that targeted training interventions explaining the multiple causes of mental illness could have an effect on representations about mental illness and associated stigma.

Researches aiming to evaluate the effect of targeted interventions on attitudes towards mental illness and using comparable measures have already taken place in the past. For example, in a previous study, a fieldwork placement of 74 Australian students working with people with mental illness in community settings resulted in more positive attitudes after completion [22]. This study used the Community Attitudes towards the Mentally Ill (CAMI) instrument [15], whose 40 statements are at the origin of the Attitudes to Mental Illness scale. The fieldwork placement had students spend one morning per week for six weeks in the community, helping consumers from community mental health centers, or running groups in the same community, with activities chosen by the consumers. In this study, contact with the mentally ill was shown to be a powerful tool in the education of future mental health professionals. It also lead to the development of more positive attitudes. In particular, after working with mentally ill people, the trainees did not perceive them to be violent nor dangerous. Finally, contact with mentally ill people seems a more powerful way of teaching students about mental health and changing their attitudes towards the mentally ill than are lectures or tutorials given by mental health professionals [22]. This finding could support the fact that the targeted training intervention that we used in our study, strongly based on users testimonies, lead to significant decrease in respondents' perception of the dangerousness of mentally ill people.

However, another research using the Community Attitudes toward the Mentally ill (CAMI) scale has shown that targeted interventions efficiency is limited by stigmatizing media messages, which have a stronger effect. In one study in the U.S., 38 students viewed a fiction film depicting mentally ill people as dangerous and an information trailer reminding them that violence is not characteristic of mentally ill persons, 48 students viewed only the fiction film, and 19 students viewed a control fiction film that was not related to mental illness [27]. The CAMI scale was completed after the viewing. Those who saw the film linking mental illness and violence expressed significantly less favorable attitudes towards mental illness and community care of mentally ill persons than did those who saw the control film, regardless of whether or not they received the corrective information trailer. These results suggest that mass media stigmatizing portrayals of mentally ill persons have the power to counteract targeted interventions. It would then be interesting to include, in analyses of the results of targeted interventions aiming to reduce stigma about mentally ill people, an analysis of the background of mainstream representations in the media at the time of study [27].

A recent study, the first population-based survey in France of its kind, asked by Internet 1000 French persons about their current awareness, knowledge and attitudes towards mental illness [9] and established that negative views about mentally ill people expressed about a mental disorder per se decrease when linked to a specific individual. It also indicated a marked contrast between views of schizophrenia, compared with other disorders such as autism or bipolar disorder, with negative stereotypes of schizophrenia prevailing. Finally, 
while respondents quoted the media as their main source of information regarding mental disorders, the authors linked these results with the worrisome media portrayals of schizophrenia, that still have a powerful influence [9].

Future initiatives to challenge stigma and discrimination should consider disorder-specific initiatives rather than general approaches to mental illnesses, and use personal testimonies and raise the visibility of individuals with mental disorders living in the community, rather than producing generic campaigns attempting to destigmatize disorders [9]. These findings suggest that initiatives of this kind hold promise.

Several limitations should be noted, especially related to the specificity and size of our sample, and to the lack of control group. This latest limitation, especially, could be significant, as other causes, independent from our study, could explain the observed changes (for example news related to mental illness in the media, or broadcasting of a movie on this subject during the same period, etc.). Another limitation lies in the significant drop-out between Time 0 and Time 1 (with less than half of the respondents remaining at Time 1), which could induce a bias linked to a selection effect.

Also, the fact that our Time 1 was assessed within a month after the intervention does not allow us to evaluate the long-term duration of the short intervention effect. Indeed, there have been some concerns in the literature about the duration over time of anti-stigma interventions [10]. However, it may be that an in-person meeting with a psychiatric services user, with the emotions expressed during these personal testimonies, has more chances of being memorable than a generic media campaign.

Regarding the suitability of the scale that we have used for measuring a reduction of stigma, an important limitation is that it is not a stigma scale per se, but more a measure of the attitudes towards mentally ill people and mental illness. The scale is however considered as a good measure to track changes in attitudes towards mental illness, and is regularly used to evaluate the effect of anti-discrimination campaigns in the U.K. In the objective of using it as a measure for the reduction of stigma in a pre - post study, we have reversed the scoring of 14 items, so that every item looked negative and stigmatizing, a method which might offer some bias. Also, we performed a factor analysis, with a Varimax rotation method, and although the factors found in our analysis correspond to the dimensions of the original scale, a few differences were identified in some rare items. This could probably be explained by the small size of our sample and the fact that it is mostly constituted in women and educated people with prior training in the health sector, whereas the original English sample is very large and representative of the general sample. Finally, when using this measure, social desirability bias should be acknowledged as well.

Further research would therefore be needed to confirm our results, on a less specific and larger sample, and with a control group. Nevertheless, the methodology and the instrument used seem promising, in the context of the measurement of attitudes towards mental illness in France.

\section{Conclusion}

The main interest of our study is to explore the potential efficiency of initiatives like a short intervention in reducing the stigma about mentally ill people among health administrators and students. This seems especially important knowing that, during their career, these professionals and future professionals could play a strategic role in mental health care and towards system users suffering from mental illness. More specifically, this research study suggests, like prior research conducted in other countries, the likely adequacy of targeted interventions, which would provide not only knowledge about mental illness to attendants, but also an opportunity for direct contact with mentally ill persons.

\section{Additional file}

Additional file 1: The French translation of the attitude to mental illness scale. (DOCX $15 \mathrm{~kb}$ )

\section{Abbreviation}

EHESP: Ecole des Hautes Etudes en Santé Publique

\section{Acknowledgements}

EHESP (National School of Public Health) which supported the training session and the research, the EHESP students who participated at the training and its evaluation, Arnold Magdelaine who provided advice on the evaluation method, put the questionnaire on line and furnished the results, Nadine Migne who organized the teaching session and coordinated the survey, Mathilde Husky, who kindly revised the language.

\section{Funding}

The training program has been funded by the EHESP, while the research and writing of the paper have been funded by Fondation Pierre Deniker, which is a non profit organisation involved in fighting stigmatisation in the mental health sector and who is totally independent from EHESP. Neither EHESP nor Fondation Pierre Deniker had any role in the design of the research, the collection, analysis and interpretation of data and the writing of the manuscript.

Availability of data and materials

Anonymized datasets are available at the following general repository: https://figshare.com/s/a231986b399c99ab65eb

\section{Authors' contribution}

MV drafted the paper and conducted the analyses, VKM directed the project, conducted the teaching session, provided the methodology, and participated at the writing. Both authors read and approved the final manuscript.

Competing interests

The authors declare that they have no competing interests. 


\section{Consent for publication}

Not applicable.

\section{Ethics approval and consent to participate}

The paper is based on a study proposed during an optional training session approved by the EHESP Education Council on 2/6/2009 and on 11/04/2012. The study was approved and conducted online by the EHESP Pedagogic Innovation Directorate, independent of the teachers and in charge of Ethics. Information about the study was given verbally by teachers and also through a Letter to the students explaining that completion was neither mandatory nor a condition for validation of the session, and guaranteeing anonymity. Consent was then obtained electronically, the students being able to refuse to participate or to accept and fill the questionnaire. The study was carried out in compliance with the Helsinki declaration, the rules in application in France, and the ethical guidelines of the EHESP, which follows the rules of the European Association for Quality Assurance in Higher Education (ENQA) and is evaluated by the Agency for Public Health Education Accreditation (APHEA).

\section{Publisher's note}

Springer Nature remains neutral with regard to jurisdictional claims in published maps and institutional affiliations.

\section{Author details}

${ }^{1}$ Fondation Pierre Deniker, 36 avenue Raymond Poincaré, Paris, France. ${ }^{2}$ Laboratoire de Psychopathologie et Processus de Santé, Paris Descartes University, Paris EA4057, France. ${ }^{3}$ Ecole des Hautes Etudes en Santé Publique, Paris, France.

\section{Received: 24 May 2016 Accepted: 31 March 2017}

\section{Published online: 08 April 2017}

\section{References}

1. Sartorius N, Schulze H. Reducing the stigma of mental illness: a report from a global programme of the world psychiatric association. By N. Sartorius and H. Schulze. Cambridge University press: Cambridge, UK. 2005. Psychol Med. 2006:36(02):279-80

2. Thornicroft G. Shunned: Discrimination against people with mental illness. Oxford: Oxford University Press; 2006.

3. Link BG, Struening EL, Rahav M, Phelan JC, Nuttbrock L. On stigma and its consequences: evidence from a longitudinal study of men with dual diagnoses of mental illness and substance abuse. J Health Soc Behav. 1997;38(2):177-90.

4. Ritsher JB, Phelan JC. Internalized stigma predicts erosion of morale among psychiatric outpatients. Psychiatry Res. 2004;129(3):257-65.

5. Jorm AF. Mental health literacy. Public knowledge and beliefs about mental disorders. Br J Psychiatry J Ment Sci. 2000;177:396-401.

6. Kelly CM, Jorm AF. Stigma and mood disorders. Curr Opin Psychiatry. 2007;20(1):13-6.

7. Read J, Haslam N, Sayce L, Davies E. Prejudice and schizophrenia: a review of the mental illness is an illness like any other approach. Acta Psychiatr Scand. 2006;114(5):303-18.

8. Dumesnil $H$, Verger P. Public awareness campaigns about depression and suicide: a review. Psychiatr Serv. 2009;60(9):1203-13.

9. Durand-Zaleski I, Scott J, Rouillon F, Leboyer M. A first national survey of knowledge, attitudes and behaviours towards schizophrenia, bipolar disorders and autism in France. BMC Psychiatry. 2012;12(1):1-8.

10. Lamboy B, Saias T. Réduire la stigmatisation des personnes souffrant de troubles psychiques par une campagne de communication? Une synthèse de la littérature. Ann Med-Psychol. 2013;171(2):77-82.

11. Perry J, Watkins M, Gilbert A, Rawlinson J. A systematic review of the evidence on service user involvement in interpersonal skills training of mental health students. J Psychiatr Ment Health Nurs. 2013;20(6):525-40.

12. Penn $D$, Couture S. Interpersonal contact and the stigma of mental illness: a review of the literature. J Ment Health. 2003;12(3):291-305.

13. Goulet M-H, Larue C, Chouinard C, Stip E, Caron J, Pelletier J-F, et al. Partage du savoir expérientiel: regard sur la contribution des patients partenaires denseignement en sciences infirmières. Santé Ment Au Qué. 2015;40(1):53-66.

14. Patten SB, Remillard A, Phillips L, Modgill G, Szeto AC, Kassam A, et al. Effectiveness of contact-based education for reducing mental illness-related stigma in pharmacy students. BMC Med Educ. 2012;12:120.
15. Taylor SM, Dear MJ. Scaling community attitudes toward the mentally ill. Schizophr Bull. 1981;7(2):225-40.

16. Cohen J, Struening EL. Opinions about mental illness in the personnel of two large mental hospitals. J Abnorm Soc Psychol. 1962;64(5):349-60.

17. Mehta N, Kassam A, Leese M, Butler G, Thornicroft G. Public attitudes towards people with mental illness in England and Scotland, 1994-2003. Br J Psychiatry J Ment Sci. 2009;194(3):278-84.

18. Taylor Nelson Sofres. Attitudes to mental illness 2014 research report. Prepared for time to change. [Internet]. Department of Health; 2015. Available from: https://www.time-to-change.org.uk/sites/default/files/ Attitudes_to_mental_illness_2014_report_final_0.pdf. Accessed 15 Apr 2015.

19. Pattyn E, Verhaeghe M, Bracke P. Attitudes toward community mental health care: the contact paradox revisited. Community Ment Health J. 2013;49(3):292-302.

20. Angermeyer MC, Millier A, Rémuzat C, Refai T, Toumi M. Attitudes and beliefs of the French public about schizophrenia and major depression: results from a vignette-based population survey. BMC Psychiatry. 2013;13:313.

21. Taylor Nelson Sofres. Attitudes to mental illness 2012 research report. Prepared for Time to Change. [Internet]. Department of Health; 2013. Available from: http://www.scie-socialcareonline.org.uk/attitudes-to-mentalillness-2012-research-report-prepared-for-time-to-change-september-2013/r/ a11G0000002z1EflAl. Accessed 15 Apr 2015.

22. Gilbert J, Strong J. Clinical placement in mental health: effects on the attitudes of students. Occup Ther Ment Health. 2000;16(2):45-58.

23. Nordt C, Rössler W, Lauber C. Attitudes of mental health professionals toward people with schizophrenia and major depression. Schizophr Bull. 2006;32(4):709-14

24. Schulze B. Stigma and mental health professionals: a review of the evidence on an intricate relationship. Int Rev Psychiatry. 2007;19(2):137-55.

25. Wolff G, Pathare S, Craig T, Leff J. Community knowledge of mental illness and reaction to mentally ill people. Br J Psychiatry J Ment Sci. 1996; 168(2):191-8.

26. Mann CE, Himelein MJ. Factors associated with stigmatization of persons with mental illness. Psychiatr Serv. 2004;55(2):185-7.

27. Wahl OF, Lefkowits JY. Impact of a television film on attitudes toward mental illness. Am J Community Psychol. 1989;17(4):521-8.

\section{Submit your next manuscript to BioMed Central and we will help you at every step:}

- We accept pre-submission inquiries

- Our selector tool helps you to find the most relevant journal

- We provide round the clock customer support

- Convenient online submission

- Thorough peer review

- Inclusion in PubMed and all major indexing services

- Maximum visibility for your research

Submit your manuscript at www.biomedcentral.com/submit
C BioMed Central 